\title{
Isoprene and monoterpene emissions from a mixed temperate forest.
}

Quentin Laffineur (1), Bernard Heinesch (1), Crist Amelynck (2), Niels Schoon (2), Jean-françois Müller (2), Jo Dewulf (3), Herman Van Langenhove (3), Eva Joó (3), Kathy Steppe (4), and Marc Aubinet (1)

(1) Biosystems Physics Unit, Gembloux Agro-Bio Tech, University of Liege, Gembloux, Belgium (q.laffineur@ulg.ac.be), (2) Belgian Institute for Space Aeronomy, Brussels, Belgium, (3) Research Group Environmental Organic Chemistry and Technology (EnVOC), Faculty of Bioscience Engineering, Ghent University, Ghent, Belgium, (4) Laboratory of Plant Ecology, Faculty of Bioscience Engineering, Ghent University, Ghent, Belgium

Isoprene (IP) and monoterpenes (MTP) are the most abundant biogenic volatile organic compounds (BVOCs) emitted by terrestrial vegetation, particularly by forests. Global IP and MTP emissions are estimated to be 460

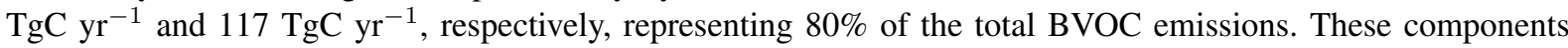
have a significant impact on atmospheric chemistry and physics.

Long term ecosystem-scale BVOC flux measurement is the sole method allowing quantification and description of BVOC emission responses to episodic events like budburst or stress; follow up of emission during vegetation growth and analysis of interaction with climate and environment. We will analyse the IP and MTP fluxes measured above a mixed temperate forest in order to illustrate the interest of long-term flux measurements by investigating the main driving variables and the underlying mechanisms of emission, how de novo carbon allocation to the isoprene/monoterpenes skeleton structure is altered through time. A disjunct eddy covariance system was installed at the forested site of Vielsalm (Belgium) from July to October 2009 and from April to October 2010 covering thus most of the vegetation season (spring, summer and first part of autumn). The system was completed by micrometeorological measurements and an eddy covariance system measuring continuously $\mathrm{CO}_{2}$ and $\mathrm{H}_{2} \mathrm{O}$ fluxes.

During the day, IP and MTP fluxes were mainly controlled by air temperature and light. This behavior resulted largely from a response of IP and MTP flux to photosynthesis itself. Indeed, a strong linear relation was found between these fluxes and the Gross Primary Production. In addition to these responses, a flux seasonal evolution was observed: a decrease in the standard emission factor was observed, probably due to acclimation or senescence. The standard emission factor $\left(30^{\circ} \mathrm{C}, 1000 \mu \mathrm{mol} \mathrm{m}{ }^{-2} \mathrm{~s}^{-1}\right)$ varied from $0.91 \pm 0.01$ to $0.56 \pm 0.02 \mu \mathrm{g} \mathrm{m}^{-2} \mathrm{~s}^{-1}$ for IP fluxes and from $0.74 \pm 0.03$ to $0.27 \pm 0.03 \mu \mathrm{g} \mathrm{m}^{-2} \mathrm{~s}^{-1}$ for MTP fluxes.

During the night, IP flux was zero but a slight positive MTP flux was observed that seemed to be driven by air temperature. These night emissions were probably due to the volatility of monoterpenes stored in the needle resin ducts of coniferous species. There could also be a contribution from the soil through litter decomposition, from roots or from micro-organisms. The standard emission factor $\left(30^{\circ} \mathrm{C}\right)$ for night-time MTP fluxes was equal to $0.093 \pm 0.019 \mu \mathrm{g} \mathrm{m}^{-2} \mathrm{~s}^{-1}$. 